\title{
A INSTRUÇÃo PÚBLICA DO SERRO/MG COMO MICROCOSMO DA EDUCAÇÃO BRASILEIRA (1821-1840)
}

\author{
Danilo Arnaldo Briskievicz*
}

\begin{abstract}
RESUMO: A história da educação brasileira no período entre 1821 e 1840 é analisada a partir de um microcosmo que é a cidade do Serro/MG, antiga vila do ouro do século XVIII. Por apresentar características próprias como a permanência do padroado como estrutura de poder local, o discurso das elites locais sobre a modernização da educação brasileira e uma constante iniciativa de introdução e manutenção da instrução pública, em especial de primeiras letras, acreditamos que a cidade mineira é como um microcosmo da educação em território nacional. A metodologia baseia-se no mapeamento, coleta e análise de documentos de arquivos públicos e particulares bem como da leitura dos livros de autores especializados no tema. O resultado obtido é que apresentamos um microcosmo da educação nacional do período de 1821-1840 a partir da cidade-sede da Comarca do Serro do Frio.

PALAVRAS-CHAVE: História da educação; História do Brasil; Trabalho docente; Cotidiano escolar.
\end{abstract}

\section{Serro/MG public instruction as a microcosm of Brazilian education (1821-1840)}

ABSTRACT: The history of Brazilian Education in the period between 1821 and 1840 is analyzed from a microcosm that is the city of Serro/MG, an ancient gold village of the eighteenth century. Because of its own characteristics such as the permanence of the patronage as a local power structure, the discourse of the local elites on the modernization of Brazilian Education and a constant initiative to introduce and maintain public education, especially the first letters, we believe that the city of Minas Gerais is as a microcosm of education in national territory. The methodology is based on the mapping, collection and analysis of documents of public and private archives as well as reading the books of authors specialized in the subject. The result is that we present a microcosm of national education from the period 1821-1840 from the most important city of Comarca do Serro do Frio. KEYWORDS: History of Education; History of Brazil; Teaching work; School daily.

\section{La instrucción pública do Serro/MG como microcosmo de la educación brasileña (1821-1840)}

RESUMEN: La historia de la educación brasileña en el período entre 1821 y 1840 es analizada a partir de un microcosmos que es la ciudad del Serro/MG, antigua villa del oro del siglo XVIII. Por presentar características propias como la permanencia del patrocinio como estructura de poder local, el discurso de las elites locales sobre la modernización de la educación brasileña y una constante iniciativa de introducción y mantenimiento de la instrucción pública, en especial de primeras letras, creemos que la ciudad minera es como un microcosmos de la educación en territorio nacional. La metodología se basa en el mapeo, recolección y análisis de documentos de archivos públicos y particulares, así como de la lectura de los libros de autores especializados en el tema. El resultado es que presentamos un microcosmos de educación nacional del período 1821-1840 de la ciudad más importante de Comarca do Serro do Frio.

PALABRAS CLAVES: Historia de la educación; Historia de Brasil; Trabajo docente; Cotidiano escolar.

\footnotetext{
*Doutor em Educação pela Pontifícia Universidade Católica de Minas Gerais. Atualmente é Professor de Filosofia e Sociologia do Instituto Federal de Minas Gerais, campus Santa Luzia/MG. Contato: Rua Érico Veríssimo, 317, CEP: 33115-390, Santa Luzia-MG, Brasil. E-mail: doserro@hotmail.com. ORCID: http://orcid.org/0000-0002-7652-1959.
} 


\title{
Introdução
}

O período compreendido entre 1821 e 1840 foi marcado por várias mudanças na estrutura política do Brasil que causaram mudanças na educação. Desde a proclamação da independência no dia 07 de setembro de 1822, quando Dom Pedro I foi proclamado imperador do Brasil, passando por seu retorno à Portugal e a abdicação de seu trono para seu herdeiro, Dom Pedro II, em 1831, avançando pelo período regencial até o golpe da maioridade de Dom Pedro em 1840, houve vários aprendizados para a cidadania brasileira. De fato, nesse período intensificou-se a participação da sociedade civil nos debates relacionados aos rumos nacionais, especialmente os da educação formal. É o que podemos designar, assim como explica Durkheim, como o momento da efervescência:

\begin{abstract}
Além desses estados passageiros ou intermitentes, há outros mais duráveis, nos quais essa influência fortalecedora da sociedade se faz sentir com maior continuidade e, com frequência, com maior intensidade. Há certos períodos históricos nos quais, sob a influência de algum grande abalo coletivo, as interações sociais se tornam mais frequentes e mais ativas. Os indivíduos se reúnem mais. Resulta disso uma efervescência geral, característica das épocas revolucionárias ou criadoras. Ora, essa superatividade tem por efeito uma estimulação geral das forças individuais. Se vive mais e de forma diferente do que nos tempos normais. As transformações não são apenas de nuanças, de graus; o homem realmente se torna outro. As paixões que o agitam são de tal intensidade que ele não pode satisfazê-las senão mediante atos violentos, desmesurados: atos de heroísmo sobre-humano ou de barbárie sanguinária. Sob a influência da exaltação geral, vemos o mais medíocre ou mais inofensivo burguês seja em herói, seja em carrasco. (DURKHEIM, 1968, p. 300-301 apud WEISS, 2013, p. 397).
\end{abstract}

A independência brasileira provocou uma mudança imediata na Vila do Príncipe. Os padres que tomavam conta da Paróquia Nossa Senhora da Conceição - pactuados com o governo pelo padroado - pediram a mudança do pelourinho da porta da Igreja Matriz na Rua Direita para ser instalado de frente da cadeia. Isso ocorreu "visto ser aí lugar mais próprio e ser justa a mudança por se achar o mesmo próximo e quase defronte da Matriz desta Vila" (SILVA, 1928, p. 39). A igreja não devia se envolver com os criminosos, mas com aqueles que quisessem a salvação de suas almas. $\mathrm{O}$ ritual de açoite no pelourinho não condizia com o ambiente sagrado da Matriz, no centro da vila. Teria sido uma ideia de Dom Frei José da Santíssima Trindade que visitara a Vila do Príncipe em 1821 e depois em 1825 para correição? Não sabemos pelos registros escritos. Contudo, devemos a ele um relato aristocrático sobre a Matriz da Vila do Príncipe e algumas referências sobre as condições da civilização serrana:

A igreja desta matriz, sendo grande e com 5 altares, pode-se dizer que está desprovida de tudo. No ano em que foi visitada, apenas tinha de ornato a boa 
imagem de Nossa Senhora da Conceição, sua padroeira colocada no princípio do trono, o qual, com o retábulo de telha pouco agradável, ainda estava em madeira. No corpo da igreja, desde o arco da capela mor corriam 3 altares todos por acabar e, do outro lado, um ou dois, cujas imagens do seu orago eram pintadas em tábuas lisas. Hoje, no ano de 1825, consta que a muitas reclamações de Sua Excelência trabalham nos retábulos destes altares, estando ainda todo o corpo da igreja por forrar e o campamento muito mal seguro e bastante destruído. A sacristia muito falta de ornamentos tanto para o comum como para os dias festivos. Não tinha adro nem cemitério, sepultando-se os corpos na passagem pública e, apesar das grandes instâncias e recomendações que fez Sua Excelência Reverendíssima para se fazer cemitério separado e profanar-se a antiga sepultura dos pobres, sabe-se que ainda nada se providenciou até este tempo. O número das almas que pelo mapa do reverendo pároco pertencem à aplicação da matriz é de 8.000 , das quais são curadas pelo mesmo pároco Manuel Joaquim Perpétuo, o Reverendo Bento de Araújo Abreu, padre Silvério Teixeira Coelho, o Reverendo Doutor Vigário da Vara Manuel Francisco da Silva, Joaquim Pedro de Cássia, escrivão do Cartório Eclesiástico e o seu promotor (TRINDADE, 1998, p. 95-96).

Dom Frei José da Santíssima Trindade em suas visitas pastorais esqueceu de anotar um problema crônico da Vila do Príncipe, em processo de resolução naquele período: o abastecimento de água potável para a população que crescia constantemente, ocupando os morros. O chafariz da Purificação, por exemplo, ficou pronto somente em 1828, assim como o da Cavalhada, a região comercial do século XIX que perdura até os dias atuais.

Assim como o temor à Igreja, as elites serranas continuavam a propagar a sua submissão inquestionável ao governo monárquico de Dom Pedro I a partir do Senado da Câmara, como se lê no edital de 11 de outubro de 1822 :

O Senado da Câmara desta Vila certo dos honrosos sentimentos dos habitantes desta Comarca, tem determinado aclamar amanhã, 12 de outubro do corrente, o nosso Augusto Defensor, o primeiro Imperador Constitucional do Brasil, e por isso roga a todos os cidadãos hajam de comparecer nos Paços do Conselho para prestarem o seu consentimento e assistirem a solenidade desse augusto ato, às 10 horas da manhã, e espera que todos se não neguem para esta ação não só com sua pessoa, como com todas as demonstrações que puderem e quiserem dar da pública alegria, iluminando a frente de suas casas nos dias 12 a 14 . Vila do Príncipe, 11 de outubro de 1822 (SILVA, 1928, p. 148).

Para agitar o contexto do padroado e da política de submissão institucional na Vila do Príncipe, houve o crescimento da imprensa jornalística que incentivou a circulação de ideias políticas das mais diversas camadas sociais, centradas na ampliação das liberdades individuais ou mesmo na rediscussão do papel da Igreja no padroado, que continuou operando como dispositivo de controle social na Comarca do Serro do Frio, cuja a cabeça da comarca, a Vila do Príncipe/Serro, teve importante papel na reelaboração no jeito brasileiro de pensar e fazer política. Assim,

[...] com o advento do Império, as províncias continuaram divididas em comarcas, cuja sede tinha a denominação de cabeça de comarca. Estas eram subdivididas em 
termos das vilas ou cidades (termos judiciários), que, por sua vez, subdividiam-se em distritos", esclarecem Martins e Soares (2016, v. 1, p. 58).

De certa maneira, a Vila do Príncipe - que mudaria seu nome para cidade do Serro em 1838 - refletiu como um microcosmo nacional os dilemas da cidadania do Brasil independente nesse contexto de mudanças no governo central, articulado a partir da cidade do Rio de Janeiro, a corte da monarquia nacional. As marcas locais: a perpetuação do padroado, a organização das elites serranas em torno do Senado da Câmara e um desejo de modernização da Vila do Príncipe pela educação formal de qualidade a fim de promover o acesso de seus filhos às instituições governamentais.

A educação passou a ser um projeto do estado brasileiro a ser discutido, implementado, debatido e reavaliado. Assim, em 03 de maio de 1823 foi instalada a primeira Assembleia Constituinte do Brasil independente composta por procuradores gerais das províncias. Segundo Chizzotti (2005, p. 31), “[...] a Constituinte de 1823 sintetiza as relações de forças sociais e políticas que, por fraturas diversas, deram condições à independência" e por sua vez "condensa as tensões geradas entre antigos aliados que porfiaram, após a partida de D. João VI, a hegemonia política no Brasil, Reino Unido.” Devido aos conflitos internos em especial entre portugueses e brasileiros - Dom Pedro I resolveu dissolver a assembleia em 12 de novembro de 1823, e acabou por outorgar uma Constituição com características especiais, em 12 de novembro de 1824. No texto, a instrução primária apareceu como um direito de todos os brasileiros uma vez que a instrução primária seria, então, gratuita (SAVIANI, 2013, p. 123).

A gratuidade da instrução primária prevista pela Constituição de 1824 é o ponto de partida para a problematização da educação na Comarca do Serro do Frio, em especial na Vila do Príncipe e seu termo, a fim de compreendermos os conflitos em torno de sua trajetória enquanto fenômeno social. Foi por ela que "a instrução pública foi considerada um direito civil e político da nova nação, contudo a cidadania incluía apenas os nascidos livres, os naturalizados e os libertos" (CURY, 2014, p. 25) e por conta disso "o acesso à instrução primária pública era interdito aos escravos e índios” (CURY, 2014, p. 25). Não podemos nos esquecer do contexto da instrução pública da província de Minas Gerais. No dia 15 de fevereiro de 1827, Bernardo Pereira de Vasconcelos expôs a situação da instrução pública ao Conselho do Governo Provincial, responsável por implementar, incentivar e fiscalizar a criação e o funcionamento das aulas no território mineiro. Segundo Mourão (1959, p. 4-7), havia "apenas 33 escolas oficiais de primeiras letras, com uma frequência de 1.107 alunos, sendo cada professor pago a razão de $150 \$ 000$ anuais" e "170 escolas particulares primárias, 
mostrando este número a grande falta de estabelecimentos oficiais de instrução.” A instrução clássica ou secundária contava com "17 aulas de latim, 1 de Retórica, 1 de Lógica" e existia também o ensino técnico com uma aula de Anatomia e outra de Desenho." Conclui que "não houve, pois, modificações de vulto, até o ano de 1835, quando foi feita a primeira lei orgânica do ensino primário, em Minas."

Afinal, a educação formal passou a ser importante para as populações da Comarca do Serro do Frio? Como se organizou o acesso a esta educação dita gratuita? Como era organizado minimamente o cotidiano dos professores e alunos nesse contexto? Qual o papel social da educação formal na Vila do Príncipe/Serro? As respostas sobre a educação na Vila do Príncipe nos auxiliam na compreensão das dificuldades cotidianas da educação brasileira e ilustram os avanços e conflitos desse contexto de aprendizado constante para a cidadania nacional.

\section{A educação formal como projeção social}

Em 23 de junho de 1825, o presidente da província de Minas Gerais, cuja capital era a Vila Rica, enviou aos oficiais da Câmara da Vila do Príncipe um ofício solicitando notícias atualizadas sobre a extensão dos termos, distritos e paróquias; a propriedade das sesmarias e terras devolutas; a fertilidade dos solos; o cultivo de gêneros de primeira necessidade; sobre a navegação dos rios; as enfermidades dominantes, entre outras informações relevantes para a compreensão dos problemas nacionais. A resposta da Câmara ao governo foi enviada em ofício datado de 23 de agosto de 1825. Segundo a descrição dos oficiais, no parágrafo quinto, pergunta primeira e segunda, questionou-se sobre o estado da instrução pública que era o seguinte, segundo o autor da resposta:

O estado da instrução pública, com declaração dos mestres, número dos discípulos, e seu aproveitamento? E principalmente se os mestres são assíduos no ensino e cuidadosos no cumprimento de seus deveres. Resposta. Em resposta a estes dois quesitos apresentamos quanto ao primeiro os dois ofícios, tanto do professor de Gramática como de Primeiras Letras, residentes nesta Vila dos quais conta o número de seus discípulos; sendo certo, que aquele é assíduo no cumprimento de seus deveres; este porém atendendo a sua avançada idade não pode em obséquio da verdade pôr-se em paralelo com o outro nem mesmo lhe quadra o epíteto dado a aquele. Além deste dois há mais três cadeiras de gramática latina, uma na Conceição que se acha ocupada por Joaquim Patrício, e de quem esta Câmara tem informações pouco agradáveis. Outra no Tijuco de quem se acha encarregado o padre Joaquim Gomes de Carvalho; e outra no Rio Preto a cargo do professor José Paulo Dias Jorge. Além destas, unicamente sabemos da existência de duas cadeiras de primeiras letras, uma na Conceição, e outra no Rio Vermelho, aquela exercida por José Joaquim Bento de Oliveira, es esta pelo padre Marcos Vaz Mourão. Ultimamente ainda que o estado da instrução pública tenha ido em progresso, digo em progressivo aumento, ainda se não acha no estado de perfeição desejada o que se deve atribuir 
em grande parte a respeito do método, e modo de ensinar (ARQUIVO PESSOAL MARIA EREMITA DE SOUZA, Caderno 4, s.p.).

O ofício acima citado esclarece a existência de dois professores atuantes na Vila do Príncipe: um professor de gramática latina e outro de primeiras letras. O professor de latim, que normalmente lecionava também o idioma francês, era Francisco de Paula Coelho de Magalhães. O professor de primeiras letras era o serrano, alfaiate e tenente Antônio Gomes Chaves, já velho e doente para dar conta de suas aulas. A vida dos dois mestres não estava fácil: o de primeiras letras em 1829 foi aposentado; o de gramática latina achava-se, em 1828, "privado de exercer as funções de seu magistério por causa de moléstias que padece" (ARQUIVO PESSOAL MARIA EREMITA DE SOUZA, Caderno 24, s.p.). Para substituí-lo foi nomeado o padre Justiniano da Cunha Pereira. Os mestres eram considerados ultrapassados em seus métodos. Contudo, o que se evidencia é a falta de investimentos na contratação de outros mestres para a abertura de novas aulas públicas por parte do governo provincial. A renovação devia se dar pela ampliação das aulas, não apenas pela exigência de novos métodos pelos antigos mestres.

Apesar dos poucos investimentos na instrução pública da Vila do Príncipe, alguns alunos conseguiram se preparar adequadamente para prosseguirem seus estudos no Rio de Janeiro. Ao analisarmos o caso dos irmãos Ottoni logo abaixo deixamos claro que a educação formal projetava socialmente aqueles que já detinham um status social na sociedade serrana. Assim, a educação formal não era para qualquer um, ou seja, era preciso ter berço, ter nascido em famílias com condições de sobrevivência e que tivessem acesso à locomoção para os principais centros de instrução pública do Brasil. Isso reforça o caráter elitista e excludente da educação formal brasileira das primeiras décadas do século XIX.

Por isso é emblemático o caso dos quatro irmãos Ottoni que frequentaram as aulas de gramática latina do mestre Francisco de Paula Coelho de Magalhães. Téofilo, Honório, Cristiano e Jorge. Eles queriam seguir seus estudos servindo como oficiais no Exército ou na Marinha, na cidade do Rio de Janeiro (CHAGAS, 1956, p. 47). Para tanto, enviam um ofício ao imperador relatando seus estudos de língua latina e francesa, além da música. O pedido foi encaminhado com um anexo:

Francisco de Paula Coelho de Magalhães, professor de língua latina, para S. M. o Imperador e Perpétuo Defensor do Brasil - Atesto debaixo de juramento aos Santos Evangelhos, que entre os discípulos, de mais habilitação e aplicação, que existem na minha aula, são os quatro filhos de Jorge Benedito Ottoni, a saber: Teófilo, de quinze anos de idade, Honório, de treze, Cristiano, de doze, Jorge, de onze. Todos estes meninos são talentosos e aplicados, porém a habilidade de Teófilo e Cristiano é prodigiosa; basta saber-se que Teófilo em sessenta e dois dias deu conta, e se fez 
senhor do Novo Método. Com seis meses de construção, verte e entende os autores clássicos, tanto historiadores, como poetas, e à vista deste, marcha Cristiano. À vista do que se a tais talentos não faltar a preciosa cultura, estou certo que muito se pode esperar destes meninos. Para constar passei a presente de minha letra original. Vila do Príncipe, aos 2 de abril de 1823, o $2^{\circ}$ do Império do Brasil - Francisco de Paula Coelho de Magalhães (CHAGAS, 1956, p. 47-48).

Os quatro irmãos ingressaram, aos poucos, na Academia de Marinha, no Rio de Janeiro. Ao longo do século XIX o ensino militar constituiu, sobremaneira, uma oportunidade de ascensão social para a população da classe média urbana brasileira. Segundo Freyre (1959, p. 318),

Para os brasileiros de origem modesta e de condições étnica tida, em certos meios, por inferior, de se instruírem em escolas militares e a expensas do Estado; e se instruírem nessas escolas não apenas em assuntos tecnicamente militares como os políticos, sociológicos, econômicos, tornando-se rivais dos bacharéis em Direito, dos médicos, dos engenheiros, dos sacerdotes, em aptidões para o exercício de cargos públicos. [...] uma rivalidade entre esses subgrupos - os formados nas escolas militares, por um lado, e o educando nas escolas de Direito, de Medicina, de Engenharia e nos Seminários de Teologia, por outro - que veio se esboçando desde a ascendência dos militares, favorecidos pela campanha paraguaia.

Os irmãos Ottoni moraram no Rio de Janeiro na residência do tio, o poeta José Elói Ottoni (1764-1851), que serviu na Secretaria da Marinha. Teófilo Benedito Ottoni retornou à Vila do Príncipe e, no dia 4 de setembro de 1830, publicou o primeiro jornal da sede da Comarca do Serro do Frio. A Sentinella do Serro apresentava em seu cabeçalho a frase do terceiro presidente norte-americano, Thomas Jefferson: “o fim de toda associação política é a conservação dos direitos naturais e imprescindíveis do homem; estes direitos são a liberdade, a segurança, a propriedade e a resistência à opressão" (BRISKIEVICZ, 2002, p. 32). O jornal teve vida curta, encerrando sua publicação em 1832. Contudo, foi através das colunas de seu jornal que Ottoni se projetou no cenário político local e nacional. Isso ocorreu por conta de sua participação ativa na mobilização para a deposição de Dom Pedro I nos movimentos populares ocorridos de 3 a 22 de abril de 1831. Na Vila do Príncipe, Ottoni conseguiu o apoio para compor uma caixa militar com doações espontâneas de joias e serviços de um grupo de dezoito mulheres, encabeçadas por Maria Salomé Perpétua Queiroga, que ofereceram oitenta e cinco mil réis (SOUZA, 1999, p. 65). Na lista das doadoras não estava o nome de nenhuma professora. É que a instrução pública na Vila do Príncipe foi profissão exclusivamente masculina até 1847.

A modernização da instrução pública na Vila do Príncipe é um tema que no século XIX tornou-se recorrente, como na maior parte do Brasil. É que:

A organização e expansão da escolarização são um dos elementos marcantes do brasil oitocentista, em especial no período pós-independência. É nesse período que a 
associação progresso, civilização e educação ganha os discursos dos estadistas e faz da instrução pública um tema de debate. Várias questões ocupavam espaço nesses discursos como, por exemplo, quem deveria ser instruído, qual o conhecimento a ser ministrado, qual a habilitação necessária do mestre, onde estabelecer escolas, etc. Do projeto de expansão da instrução escolar básica para grande parte da população decorria a necessidade de organizá-la de maneira a atingir esse objetivo (FARIA FILHO, CHAMON, ROSA, 2006, p. 71).

Teófilo Ottoni talvez seja o exemplo mais claro de como a educação formal passou a ter sua valorização no cenário serrano. Isso deve-se ao fato do alargamento da compreensão da educação como facilitadora do acesso aos serviços públicos, seja como funcionário do corpo burocrático, seja como usuário dos seus serviços, como as escolas públicas de excelência. No caso de Ottoni, as duas coisas aconteceram ao mesmo tempo. A educação formal permitiu-lhe o acesso à Escola de Marinha e, por outro lado, possibilitou sua projeção e reconhecimento como figura política e pública através do seu jornal Sentinella do Serro, o que lhe garantiu o cargo de vereador da Câmara; de deputado provincial à Assembleia Legislativa em 1835/1838; de deputado à Assembleia Geral na Câmara dos Deputados em 1838, no Rio de Janeiro e novamente em 1845, 1848 e 1861; de senador em 1864 (CHAGAS, 1956). É importante ressaltar, seguindo a explicação dada por Faria Filho, Chamon e Rosa (2006, p. 13) que, apesar do pequeno número de exemplares impressos do jornal de Ottoni, destinado a um pequeno grupo de leitores numa vila em que a maioria da população era analfabeta de que a propagação de suas ideias se deveu ao fato de que:

Há fortes indícios de que o impacto da imprensa foi decisivo, passando a atingir um número cada vez maior de pessoas, ainda que não soubessem ler" sendo "a prática da leitura em voz alta, costume da época, quer em âmbito doméstico, quer no público, era muito difundida e valorizada.

Confirma essa informação Jinzenji (2010, p. 76), quando explica que no século XIX, era "ínfima a parcela de leitores na sociedade" o que não impedia que "a leitura em voz alta" fosse desenvolvida "nos espaços de sociabilidade e no âmbito doméstico, sendo bastante significativa por contemplar o público não leitor."

Talvez por tudo o que foi analisado anteriormente, fazendo justiça ao lugar social que a educação formal he permitiu chegar, o mesmo vereador Ottoni insistiu na implantação de "aulas de gramática latina, francês, filosofia, retórica em cada uma Comarca devendo o governo marcar a Vila onde deverão estabelecer as sobreditas aulas indico que se dirija ao Governo Provincial uma representação pedindo para ser o assento das mesmas nesta Vila" (ARQUIVO PESSOAL MARIA EREMITA DE SOUZA, Caderno 12, s.p.), o que foi unanimamente aprovado. Contudo, a modernização da instrução pública como assinalou o 
ofício da Câmara da Vila do Príncipe passava pela introdução de novos métodos de ensino e isso foi alcançado, pelo menos formalmente, com a adesão do governo provincial e por extensão das inspetorias da instrução pública de Minas Gerais ao ensino mútuo. Ottoni aprendera que a educação formal poderia mudar a história dos serranos.

\section{O ensino mútuo}

O Decreto Imperial de 15 de outubro de $1827^{1}$ foi a primeira lei geral relativa ao ensino elementar no Brasil do Primeiro Reinado (BRAZIL, 1827). Trata-se de dezessete artigos que instruem sobre a descentralização do ensino mandando abrir escolas em todas as cidades, vilas e lugares mais populosos do Império; a remuneração dos professores prevista no artigo $3^{\circ}$ determinou que os presidentes provinciais taxassem os vencimentos dos professores, regulando-os de $200 \$ 000$ a $500 \$ 000$ anuais, com atenção às circunstâncias da população e carestia dos lugares; a adoção do ensino mútuo; a constituição de um currículo mínimo; o processo de admissão de professores e as escolas das meninas. No artigo primeiro, as escolas de primeiras letras passaram a ser obrigadas a ensinar para os meninos, a leitura, a escrita, as quatro operações de cálculo e as noções mais gerais de geometria prática. Por outro lado, para as meninas, foram excluídas as noções de geometria. Elas aprenderiam as prendas costurar, bordar, cozinhar - para a prática da economia doméstica.

A modernização da instrução pública com o ordenamento jurídico para sua criação e funcionamento dado pela lei imperial de 1827 não cita em seus dezessete artigos a palavra pedagogia ou algum adjetivo equivalente, como bem observou Saviani (2014, p. 15), mas prescreveu a obrigatoriedade do método do ensino mútuo lancasteriano. O método do ensino mútuo tornou-se, portanto, oficialmente obrigatório. A prática docente foi diretamente afetada uma vez que exigiu-se dos mestres de primeiras letras a comprovação do domínio de doutrinas específicas que deveriam ser comprovadas por um exame oficial, anunciado na Província de Minas Gerais por um edital (ARQUIVO PESSOAL MARIA EREMITA DE SOUZA, Caderno 24, s.p.) derivado do Art. $6^{\circ}$ da lei que anunciou:

Os professores ensinarão a ler, escrever, as quatro operações de aritmética, prática de quebrados, decimais e proporções, as noções mais gerais de geometria prática, a gramática de língua nacional, e os princípios de moral cristã e da doutrina da religião católica e apostólica romana, proporcionados à compreensão dos meninos; preferindo para as leituras a Constituição do Império e a História do Brasil (BRAZIL, 1827). 
Além disso, os professores começaram a ser classificados entre os antigos e os novos, os atrasados e os modernos. Dessa forma, os vereadores da Câmara receberam a seguinte informação do governo provincial de um pedido de outros professores para modernizar o ensino público na Vila do Príncipe:

\begin{abstract}
Ofício do presidente do governo desta província para a Câmara da Vila do Príncipe. Sendo presente ao Conselho do Governo a representação dessa Câmara datada de 23 de maio do ano passado em que pretende a transferência do professor de ensino mútuo José de Queiroga Vasconcelos da Vila de São João del Rei para essa Vila declarou o mesmo Conselho que já tomara as providências necessárias para propagar o ensino mútuo de primeiras letras na forma da lei de 15 de outubro; espera que essa Câmara cumpra com a informação exigida no meu ofício de oito do corrente, portanto este mesmo lhes comunico par a devida inteligência e execução. Imperial cidade de Ouro Preto, em 15 de janeiro de 1828 (ARQUIVO PESSOAL MARIA EREMITA DE SOUZA, Caderno 24, s.p.).
\end{abstract}

Ao que tudo indica o professor pretendido pela Câmara para modernizar a instrução pública na Vila do Príncipe não chegou a ser transferido oficialmente para a mesma. Os arquivos públicos não mencionam sua atividade na vila como entrega de mapas de alunos e recebimento de seus vencimentos. O Conselho Provincial comunicou à Câmara, inclusive, que os vencimentos dos professores de primeiras letras deveria ser o seguinte:

\begin{abstract}
O mestre que ensinar até 50 discípulos terá 200 mil réis de ordenado, o que ensinar de 50 a 100 vencerá por cada um discípulo que acrescer aos 50 primeiros quinhentos réis, o que ensinar de 101 até 150 vencerá por cada um discípulo na mesma turma, seiscentos réis de 151 até 200,700 réis, de 250 até 300 deles 800 réis, de 300 para cima 1000 réis de maneira porém que nunca poderá exceder o ordenado de 500 mil réis. Deste modo, espera o Conselho que conciliando-se o interesse público com o particular e crescendo o ordenado a proporão do número de discípulos terão os mestres e mestras o maior emprenho em bem cumprir seus deveres, a fim de acarrearem maior número de discípulos que for possível [...]. 15 de março de 1828 (ARQUIVO PESSOAL MARIA EREMITA DE SOUZA, Caderno 24, s.p.).
\end{abstract}

$\mathrm{Na}$ prática, o ordenado final de um professor de primeiras letras não poderia ultrapassar 500 mil réis. De fato, de acordo com os mapas dos professores da Vila do Príncipe analisados no século XIX juntamente com as Atas de Exames das escolas, o maior número encontrado foi de 122 alunos que frequentaram as aulas, datado de 1887, da professora Bibiana Augusta de Queiroz (IPHAN, Documento 149, Caixa 32). Por esse número de alunos frequentes, a professora receberia, de acordo com os critérios acima que já não valiam em 1887, 200\$600 réis por ano para ensinar a 122 alunos pelo ensino mútuo.

O método do ensino mútuo foi adotado pelas vantagens econômicas para os cofres públicos. Esta era a lógica para o funcionamento das escolas de primeiras letras, anunciada abertamente em ofício do presidente da província de Minas Gerais aos oficiais da Câmara, 
datado de 10 de maio de 1828. Nele se explica que "por este método um mestre pode ensinar até mil discípulos, as ideias fixam melhor na memória não só por se unir o ler, o escrever, mas por ensinar os mais adiantados aos menos adiantados, fortalece-se a atenção dos preguiçosos" (ARQUIVO PESSOAL MARIA EREMITA DE SOUZA, Caderno 24, s.p.).

É que o método monitorial, lancasteriano ou de ensino mútuo tem como princípio que os alunos mais adiantados ensinem para os menos adiantados, criando multiaulas dentro do mesmo espaço de ensino-aprendizagem, organizadas pelo professor que supervisiona o processo, numa das extremidades do salão único e amplo, controlando o comportamento dos alunos. Dessa forma, "estima-se que uma classe de 200 a 250 alunos necessita de 40 monitores a escolher entre os melhores alunos e com a melhor conduta; eles são o elemento essencial do método" (GAUTHIER: TARDIF, 2014, p. 159). Além disso, fica evidente que o ensino mútuo, considerado moderno nesse contexto, tem como função "alfabetizar o maior número possível de alunos ao melhor custo e nos melhores prazos" (GAUTHIER; TARDIF, 2014, p. 157), uma vez que "há uma vontade de educar o povo, mas sabe-se perfeitamente que essa educação custa caro" (GAUTHIER: TARDIF, 2014, p. 158).

Depois da experiência do método do ensino mútuo, sobre o qual não é possível demarcar onde e de que forma foi implantado na Vila do Príncipe, uma vez que os professores pertenciam em sua maioria à classe média urbana serrana, não possuindo para suas aulas senão um cômodo de sua própria residência, fica mais fácil compreender que com o passar do tempo a prática docente será vista como eficiente se realizada para um número maior de alunos em espaços cada vez maiores. Nesse caso percebemos claramente, que os enormes prédios particulares da Vila do Príncipe serão alugados pelo governo provincial ou municipal para o funcionamento das aulas, em especial ao final do século XIX e início do século XX, acabando por serem comprados para abrigar o grupo escolar e o ginásio no século XX.

\section{Conclusão: o mundo e o imundo}

Um processo novo na política da Vila do Príncipe iniciou-se com a lei de $1^{\circ}$ de outubro de 1828 que pôs fim à forma herdada do período colonial, ou seja, do século XVIII, de organizar o poder municipal central. Os oficiais do Senado da Câmara no início do século XIX eram escolhidos por eleições indiretas, realizadas internamente entre os homens bons da Vila do Príncipe. Com a mudança na forma de escolha dos oficiais passou-se a organizar eleições diretas, com a participação popular através do voto (SILVA, 1928, p. 174). A primeira Câmara Municipal da Vila do Príncipe foi empossada no dia 03 de maio de 1829 e 
foi composta por Simeão Vaz Mourão, Alexandre José Fróis, Bento de Araújo Abreu, José Ferreira Carneiro, João Nepomuceno de Almeida, Antônio José dos Santos, Valeriano Fidélis do Carmo (ARQUIVO PESSOAL MARIA EREMITA DE SOUZA, Caderno 24, s.p.). Um dos pilares das promessas políticas dos vereadores era exatamente a modernização da Vila do Príncipe pela educação. De fato, o primeiro ofício da instituição pública eleita por voto popular foi pedir providências para o governo provincial para prover a cadeira de Primeiras Letras, decadente por conta da idade avançada do mestre de primeiras letras que acabou aposentado em 1832, recebendo metade de seus proventos (ARQUIVO PESSOAL MARIA EREMITA DE SOUZA, Caderno 24, s.p.).

A Vila do Príncipe passou por outra transformação importante no dia 06 de março de $1838^{2}$. Pela Lei Provincial n. 93 mudou o nome da antiga vila do ouro do século XVIII para a cidade do Serro (SOUZA, p. 45-46). Tratou-se uma elevação, simbolicamente representando a entrada da nova cidade na recém-inaugurada nova ordem imperial. A modernização do nome e a elevação à categoria de cidade, criou a expectativa de renovação das antigas estruturas do passado. Na educação formal, contudo, a nova ordem modernizadora parecia caminhar a passos muito lentos.

Nas primeiras décadas do século XIX a população serrana aumentou significativamente. No Censo Provincial de 1840 a cidade do Serro contava com 5.195 habitantes e aumentou esse número para 10.584 em 1858 a partir de dados estimativos do governo provincial (SOUZA, 1993, p. 116). Isso representa uma taxa de crescimento na ordem de $4 \%$. Ao contrário do que normalmente se pensa, a população cresceu além da taxa de nascimentos, ou seja, até 1850 com a proibição do tráfico de africanos escravizados por conta da publicação da Lei Eusébio de Queirós, a importação de mão de obra escrava intensificou-se, apesar da decadência da mineração. De fato, a Vila do Príncipe/Serro aumentou sua população pois a escravidão ainda significava uma importante forma de capitalização ou de acumulação (SOUZA, 1993, p. 113). O crescimento da população exigiu, também, a dinamização da produção agropecuária e o fortalecimento do comércio para o abastecimento local.

Qual foi o papel social da educação formal na sociedade serrana escravista, agropastoril e comercial na primeira metade do século XIX?

Sem dúvida, sua função social foi manter a estabilidade da economia da Província de Minas Gerais baseada na atividade agropastoril em grandes e pequenas propriedades de terras aonde se encontrava prioritariamente o trabalho escravo. A permanência de um passado 
agropastoril nos moldes coloniais contrastava com o discurso das elites locais de modernização da vida social pela educação formal popular.

O dinamismo econômico serrano produziu um discurso de modernização da educação. Nesse sentido, o ensino espontâneo dos ofícios mecânicos continuou a ser fundamental para a estratificação social serrana em que os africanos escravizados, os egressos da escravidão e as camadas pobres da população aprendiam os serviços manuais. Por outro lado, a educação formal começou a operar como um dispositivo de poder disciplinar de diferenciação socioeconômica pelo trabalho intelectual, num espaço criador de duas esferas apartadas: o mundo e o imundo. A educação serrana passou a reproduzir ainda de maneira incipiente, mas já perceptível pelo discurso institucional das elites serranas através do Senado da Câmara/Câmara Municipal, um distanciamento entre o civilizado e o não-civilizado, entre o ilustrado e o sem instrução, entre os inteligentes e os ignorantes.

A cisão social da educação formal serrana caracteriza-se pela invenção de um espaço público sagrado como o compreendia Durkheim (1989, p. 373-384). Assim, a soberania das elites serranas em relação ao seu território dividiu o processo civilizatório entre os que conseguiam transitar pelo sagrado - o mundo e aqueles que ficavam à margem desse processo - o imundo. Os que faziam parte do mundo eram sacralizados pela educação; os que ficavam à margem eram profanados pelo analfabetismo. O trabalho manual dos ofícios mecânicos, apesar de fundamental para a construção e manutenção da habitabilidade e sobrevivência dos serranos era tido como imundo, ou seja, não permitia uma ascensão social plena, pois ficava sempre a sensação de uma ausência, uma incompletude estrutural, original. Já o trabalho intelectual - e sua maior representação social que era o padre da Igreja - passou a ser perseguido como componente essencial do mundo serrano, como um destino manifesto dos fundadores da civilização das minas de ouro. Os imundos estão na civilização, mas parecem estrangeiros. Os pertencentes ao mundo estão na civilização e são naturalmente os seus proprietários e perpetuadores. A educação formal faz ampliar essa mundanidade civilizacional. Para ingressar no mundo é preciso a purificação pela educação e pela moralização dos costumes (SOUZA, 1993, 15-16). Na primeira metade do século XIX a cisão entre mundo e imundo chegou no seu momento de efervescência. Segundo Weis (2013, p. 397), para Durkheim, “[...] a moral é um fenômeno que tem uma origem social” e "portanto, inclusive os "ideais", que são o coração de todo princípio moral, são produções coletivas" uma vez que "toda reunião de grupo, assembleias, etc. é um momento dinamogênico, que contribui para reavivar a percepção dessa realidade sui generis". Contudo, "há momentos em 
que essa força atinge uma intensidade excepcional [...], justamente porque a interação entre as consciências é mais frequente e mais ativa: [...] os períodos históricos de transição são um desses momentos mais característicos" em que parece configurar-se "um abalo no mundo tal como ele é" e por isso, "os momentos de crise são particularmente férteis" pois "é essa grande concentração energética que permite criar o novo."

Para as elites serranas a educação formal de seus filhos era uma forma nova de distinção social de que Teófilo Ottoni pode ser considerado um modelo exemplar. Por conta de sua origem no interior do mundo serrano, soube ampliar sua vocação aproveitando a educação formal para se distinguir ainda mais daqueles que compunham o imundo. $\mathrm{O}$ jeito barroco serrano de ser foi inventado pela civilização serrana no século XVIII, regulada por seus valores, seus costumes, sua cosmovisão, sua religiosidade. $\mathrm{O}$ mundo então passa a ser compreendido como ancestralidade, herança, legado dos antepassados. O padroado, fundamental para a purificação do mundo e seu pleno funcionamento prático, é um dispositivo de controle e dinamização da civilização serrana. Os padres acabaram por passar para as próximas gerações o desejo pela educação formal uma vez que numa sociedade composta majoritariamente por analfabetos sabiam usar o seu trabalho intelectual para influenciar a comunidade. Não por acaso, Ottoni preferiu ir para o Rio de Janeiro estudar na Academia de Marinha para fugir ao destino dos meninos que iam imitar os padres serranos, ingressando nos seminários eclesiásticos. A educação formal acabou por se tornar uma forma de emulação das crianças e jovens, pois produzia um sentimento de que o indivíduo recémchegado ao mundo precisava se igualar ou superar outrem, através de uma competição, uma disputa, uma concorrência, nesse caso incentivados pelo ensino mútuo. Não por acaso, o ensino mútuo foi exigido pelas elites serranas: ele é uma forma de marcar os serranos mais capazes por sua inteligência a se distinguirem na civilização serrana a fim de perpetuá-la. Os imundos, os destinados ao trabalho manual por suas condições sociais, ou aqueles rejeitados pela educação formal acabavam por formar um grupo que merecia certa repugnância, por conta de sua imoralidade ou licenciosidade.

A reflexão sobre o mundo e o imundo, sobre a civilização e a barbárie, sobre os inteligentes e os ignorantes, sobre o trabalho manual e o trabalho intelectual nos remete ao cerne da educação formal nos primeiros anos do século XX. Trata-se de entender que a educação é uma forma de reprodução do poder simbólico (BOURDIEU, 2011, p. 55-72) que é uma maneira prática de conhecer o mundo em que vivemos. Enquanto instituição, a escola de instrução pública não é apenas uma sala, uma casa, um professor. A escola é um espaço de 
reprodução das relações de poder socialmente constituídas, nesse caso em tela, da constante perpetuação dos mecanismos de designação do mundo e do imundo, do sagrado e do profano. Dessa forma, a reprodução das relações sociais na escola se aproxima ao que afirma o antropólogo René Girard (1998, p. 46) quando explica que "é a violência que constitui o verdadeiro coração e alma secreta do sagrado."

Portanto, ao final do período analisado houve um golpe da maioridade em que Dom Pedro II assumiu o poder no Brasil em 23 de julho de 1840, com apenas 14 anos de idade. Na cidade do Serro, as elites serranas ainda buscavam um professor de primeiras letras. De fato, na Comarca do Serro do Frio as aulas de primeiras letras, de latim e de francês cresceram nos distritos serranos e seus povoados, expandindo a rede pública de instrução. O número de professores circulando pela Comarca criou um ambiente em que podem ser registrados os termos que até hoje são usados como nomeação de professores, edital de concurso público para provisão de vagas, vencimentos e ordenados, mapas de alunos matriculados e frequentes [censo escolar], livros ou manuais didáticos, ano escolar ou letivo, método de ensino e legislação escolar. A educação formal na Vila do Príncipe/Serro é uma demonstração de que a instrução pública tem uma história complexa com várias narrativas possíveis para compor minimamente o seu enorme caleidoscópio de experiências.

\section{Notas}

\footnotetext{
${ }^{1}$ Uma contraposição importante é o Ato Adicional à Constituição do Império de 1834 que de certa maneira desobrigou o governo central de cuidar das escolas primárias e secundárias transferindo a incumbência para os governos provinciais (SAVIANI, 2014, p. 11). Segundo Nascimento (2019, s.p.), "graças à descentralização da educação através do Ato Adicional, em 1835 surgiu a primeira Escola Normal do país, em Niterói. Em seguida outras Escolas Normais foram criadas visando melhorias no preparo do docente. Em 1836 foi criada a da Bahia, em 1845 a do Ceará e, em 1846, a de São Paulo. Em 1837, na cidade do Rio de Janeiro foi criado o Colégio Pedro II, onde funcionava o Seminário de São Joaquim. O Colégio Pedro II fornecia o diploma de bacharel, título necessário na época para cursar o nível superior. Foram também criados nessa época colégios religiosos e alguns cursos de magistério em nível secundário, exclusivamente masculinos. O colégio de Pedro II era frequentado pela aristocracia, onde era oferecido o melhor ensino, a melhor cultura, com o objetivo de formar as elites dirigentes. Por este motivo, era considerado uma escola modelo para as demais no país."

${ }^{2}$ O Art. 29 da Lei $\mathrm{n}^{\circ} 13$, de 28 de março de 1835, completada pelo regulamento $\mathrm{n}^{\circ} 3$, organizou a instrução pública em graus. Para as povoações e arraiais previa-se o funcionamento das escolas de primeiro grau e nas vilas ou cidades as de $1^{\circ}$ e $2^{\circ}$ graus. A partir desta lei a província de Minas Gerais foi dividida em 15 círculos literários, com um delegado e um suplente. Em 1839, o $5^{\circ}$ Círculo Literário tinha sede em Diamantina e abarcava a cidade do Serro (MOURÃO, 1959, p. 11-12). Por volta de 1880, a inspetoria da instrução pública da cidade do Serro coordenava $12^{\circ}$ círculo literário (ARQUIVO IPHAN SERRO, Documento 105, Caixa 05, 05/08/1880). Os mapas de aulas e as correspondências em arquivos públicos mostram uma ampla organização no interior da Comarca do Serro do Frio, à exceção de Diamantina. Assim, compunham o $12^{\circ}$ Círculo Literário: Serro e seu termo: Milho Verde, São Gonçalo do Rio das Pedras, Santo Antônio do Rio do Peixe, Itapanhoacanga, Três Barras, Capivari, Brumado do Mato Dentro, Vargem do Rio do Peixe, Peçanha, Mosquito, Santo Antônio do Itambé, Mãe dos Homens do Turvo, Nossa Senhora da Pena do Rio Vermelho, São Sebastião do Correntes, São
} 
Miguel e Almas, São José do Rio Preto, Paraúna Cocós, Quaty dos Bastos, Cabeça de Boi, São José do Quilombo, Santo Antônio do Rio abaixo, , São Domingos do Rio do Peixe, São João do Morro Grande, Catas Altas do Mato Dentro, Nossa Senhora do Patrocínio, Deliz] e Conceição do Mato Dentro e seu termo [Santa dos Ferros, Morro do Pilar, Tapera]. A comunicação era feita pelo inspetor da instrução pública da Comarca do Serro Frio que morava na Vila do Príncipe/Serro para os delegados nomeados onde quer que houvesse uma escola ou aula em funcionamento.

\section{Referências Bibliográficas}

ARQUIVO IPHAN SERRO. Documentos de Câmara. Documento 105, Caixa 05, 05/08/1880.

ARQUIVO PESSOAL MARIA EREMITA DE SOUZA. Caderno [4] 00-00-0000 Francisco de Assis Gomes Pinheiro [d], sem paginação.

ARQUIVO PESSOAL MARIA EREMITA DE SOUZA. Caderno [12] 00-00-1967 Abelha, sem paginação.

ARQUIVO PESSOAL MARIA EREMITA DE SOUZA. Caderno [24] 24-05-1973

Caderflex, sem paginação.

BOURDIEU, Pierre. O poder simbólico. 2. ed. Lisboa: Edições 70, 2011.

BRAZIL. Câmara dos Deputados. Lei de 15 de outubro de 1827. Disponível em:

<https://www2.camara.leg.br/legin/fed/lei_sn/1824-1899/lei-38398-15-outubro-1827-566692publicacaooriginal-90222-pl.html>. Acesso em: 11 abr. 2019.

BRISKIEVICZ, Danilo Arnaldo. A arte da crônica e suas anotações: história das Minas do Serro do Frio à atual cidade do Serro em notas cronológicas (14/03/1702 a 14/03/2003). Porto Alegre: Revolução E-book - Simplíssimo, 2017.

BRISKIEVICZ, Danilo Arnaldo. A arte da tipografia e seus periódicos. História da imprensa serrana das Minas do Serro do Frio à cidade do Serro. 1702-2000. Serro: Tipographia Serrana, 2002.

CHAGAS, Paulo Pinheiro. Teófilo Ottoni. Ministro do povo. 2. ed. rev. ampl. Rio de Janeiro, Livraria São José, 1956.

CHIZZOTTI, Antônio. A constituinte de 1823 e a educação. In: FÁVERO, Osmar (org.). A educação nas constituintes brasileiras, 1823-1988. Campinas/SP: Autores Associados, 2005.

CURY, Carlos Roberto Jamil. Educação e direito à educação no Brasil: uma história pelas Constituições. Belo Horizonte: Mazza Edições, 2014.

DURKHEIM, Émile. As formas elementares da vida religiosa: o sistema totêmico na Austrália. São Paulo: Paulinas, 1989. 
DURKHEIM, É. Les formes élémentaires de la vie religieuse. Paris: Presses Universitaires de France, 1968.

FARIA FILHO, Luciano de; CHAMON, Carla Simone; ROSA, Walquíria Miranda. Educação elementar. Minas Gerais na primeira metade do século XIX. Belo Horizonte: Editora UFMG, 2006.

GAUTHIER, Clermont; TARDIF, Maurice. A pedagogia. Teorias e práticas da antiguidade aos nossos dias. 3. ed. Petrópolis/RJ: Vozes, 2014.

GIRARD, René. A violência e o sagrado. Rio de Janeiro: Paz e Terra, 1998.

JINZENJI, Mônica Yumi. Cultura impressa e educação da mulher no século XIX. Belo Horizonte: Editora UFMG, 2010.

MARTINS, Lúcio Urbano Silva; SOARES, Rosane Vianna. Comarcas de Minas. Volume I. Belo Horizonte: Imprensa Oficial de Minas Gerais, 2016.

MARTINS, Roberto Borges. A economia escravista de Minas Gerais no século XIX. Belo Horizonte: $\quad$ CEDEPLAR/UFMG, $1980 . \quad$ Disponível em: <http://www.cedeplar.ufmg.br/pesquisas/td/TD\%2010.pdf>. Acesso em: 21 mar. 2019.

NASCIMENTO, Maria Isabel Moura. O império e as primeiras tentativas de organização da educação nacional (1822-1889). Disponível em:

<http://www.histedbr.fe.unicamp.br/navegando/periodo_imperial_intro.html >. Acesso em: 22 mar. 2019.

SAVIANI, Dermeval. História das ideias pedagógicas no Brasil. 4. ed. Campinas: Autores Associados, 2013.

SAVIANI, Dermeval; ALMEIDA, Jane Soares de; SOUZA, Rosa Fátima de;

VALDEMARIN, Vera Tereza. O legado educacional do século XIX. 3. ed. Campinas/SP: Autores Associados, 2014.

SILVA, Dario Augusto Ferreira da. Memória sobre o Serro Antigo. Serro: Tipographia Serrana, 1928.

SOUZA, José Moreira de. Cidade: momentos e processos. Serro e Diamantina na formação do norte mineiro no século XIX. São Paulo: Marco Zero, 1993.

SOUZA, Maria Eremita de. Aconteceu no Serro. Belo Horizonte: BDMG, 1999.

TRINDADE, Dom Frei José da Santíssima. Visitas pastorais de Dom Frei José da Santíssima Trindade (1821-1825). Belo Horizonte: Fundação João Pinheiro, 1998.

WEIS, Raquel Andrade. Do mundano ao sagrado: o papel da efervescência na teoria moral durkheimiana. Horizontes Antropológicos, Porto Alegre/RS, n. 40, p. 395-421, jul./dez. 2013. 
